\title{
Analysis of Factors Affecting the Longevity of Voice Prosthesis Following Total Laryngectomy with a Review of Literature
}

\author{
Arvind Krishnamurthy ${ }^{1} \cdot$ Suhaildeen Khwajamohiuddin ${ }^{2}$
}

Received: 19 October 2016 / Accepted: 28 August 2017 / Published online: 6 September 2017

(C) Indian Association of Surgical Oncology 2017

\begin{abstract}
Tracheoesophageal voice puncture (TEP) coupled with the use of voice prosthesis has been considered as the gold standard for speech rehabilitation in patients of advanced laryngeal/hypopharyngeal carcinomas, who have undergone a total laryngectomy with or without partial pharyngectomy. Although prosthetic voice rehabilitation is commonly practiced worldwide including India, there is a paucity of published Indian data, more so in the current era of organ conservation. This study included 60 laryngectomized patients with a prosthetic voice rehabilitation at a tertiary cancer center in South India between January 1, 2010 and December 31, 2013. Among the 60 patients, the primary site of cancer was the larynx in 43 patients and hypopharynx in the remaining 17. All patients had undergone a primary TEP insertion, 55 in the upfront setting and five in the salvage (post-radiation/chemoradiation) setting. The ability to retain a successful tracheaesophageal speech on follow-up (median 15.5 months) in our series was around $82 \%$. The mean device life of voice prosthesis in our patient cohort was 16 months. There was surprisingly no significant difference in the prosthesis device life on correlation with age, co-morbidities, habitat, literacy status, pre-operative tracheostomy, setting of surgery, and the extent of surgery. Our series has successfully demonstrated the safety and feasibility of using primary TEP coupled with the use of voice prosthesis for voice rehabilitation in properly selected and motivated patients of advanced laryngeal and
\end{abstract}

Arvind Krishnamurthy

drarvindkrishnamurthy@yahoo.co.in

1 Surgical Oncology, Cancer Institute (WIA), 38, Sardar Patel Rd, Adyar, Chennai 600036, India

2 Preventive Oncology, Cancer Institute (WIA), 38, Sardar Patel Rd, Adyar, Chennai 600036, India hypopharyngeal carcinomas across all clinical settings. A mean device life of 16 months makes prosthetic voice rehabilitation, an attractive as well as a financially viable option for patients in a resource constrained setting.

Keywords Voice prosthesis - Tracheoesophageal voice puncture · Total laryngectomy · Carcinoma larynx · Carcinoma hypopharynx $\cdot$ Voice rehabilitation

\section{Introduction}

Total laryngectomy with or without partial pharyngectomy is a procedure of choice in moderately advanced carcinoma of the larynx/hypopharynx in primary setting. With the advent of effective organ preservation protocols like chemo-radiation, the role of total laryngectomy has steadily declined over the years. Despite these trends, a sizable number of patients have to undergo a laryngectomy as a result of failure of organ preservation protocols of due to primary advanced disease. The surgical procedure of total laryngectomy significantly alters the speech mechanics. For a normal speech, three basic elements are considered necessary, i.e., a power source, a sound source, and a sound modifier. For individuals with an intact larynx, the air from the lung is the power source, the larynx is the sound source, and the vocal tract is the sound modifier. During the performance of a total laryngectomy, the sound source (larynx) is removed and the power source (lungs) is disconnected from the sound modifiers (pharyngoesophageal segment). Over the years tracheoesophageal voice puncture (TEP) coupled with the use of voice prosthesis has become the gold standard for speech rehabilitation in patients who have received total laryngectomy [1-10]. Although prosthetic voice rehabilitation is commonly practiced in major centers worldwide, there is sparse published Indian data in literature. 
We share our experience of voice rehabilitation with primary TEP coupled with the use of voice prosthesis in tertiary cancer care center in South India with an emphasis on the voice prosthesis device life in the era of organ conservation.

\section{Material and Methods}

Sixty consecutive patients with laryngeal and hypopharyngeal cancer treated with total laryngectomy with or without partial pharyngectomy and primary TEP coupled with the use of voice prosthesis for voice rehabilitation in tertiary cancer center between 2010 and 2013 formed our study cohort. Data pertaining to the patient's demography, pre-operative tracheostomy, setting of surgery (primary or salvage), extent of surgery, concomitant neck dissection, life of prosthesis, complications associated with prosthesis, and follow-up data were abstracted and analyzed.

Post-laryngectomy prior to the creation of the neo-pharynx, the Provox® I/II voice prosthesis (Atos Medical AB, Hörby, Sweden) was inserted. The patients who underwent upfront surgery received adjuvant radiation/chemoradiation as per standard guidelines. The patients were followed up 1-2 monthly for the first year and 3 monthly for the second year and six monthly from the third year onwards. All patients received pre-operative counseling and instructions on postoperative hygiene and maintenance of prosthesis by a dedicated speech therapist. More recently, we have shifted to the routine use of Provox Vega prosthesis. The success of TEP was measured as consistency of using voice prosthesis as primary mode of communication and the duration of device life and failure was recorded in months.

\section{Results}

In 43 of the 60 patients, the primary site of cancer was in the larynx, while 17 patients had their primary in the hypopharynx. Barring one patient of sarcoma of the larynx, all the patients were histologically proven squamous cell carcinomas. The mean age of our cohort was 56 years (mean 3173 years). There was a significant male preponderance ( 56 male and four female patients), of which 41 patients $(68 \%)$ had at least secondary level of education. Twenty-two [36.6\%] patients had undergone a pre-operative tracheostomy. All patients had undergone a primary TEP insertion, 55 in the upfront setting and five in the salvage (post-radiation/chemoradiation) setting. The tumor stage distribution was mentioned in Table 1. The voice prosthesis has to be removed in two patients within a month following surgery, both of whom had to undergo re surgery, one for a secondary hemorrhage and the other for a spinal stabilization due to an unrelated event of vertebral collapse.
Forty-three patients received adjuvant radiation therapy, while four patients received adjuvant chemo-radiation. Seven patients were planned for adjuvant radiotherapy, but the same could not be administered either due to patient refusal or defaulting for treatment (including the patient who developed cervical vertebral collapse post-operatively and was not advised radiation due to delay after spine stabilization). Ten (16.6\%) patients recurred loco-regionally, and two (3.3\%) had distant metastasis on follow-up. The follow-up ranged from 1 to 50 months with median follow-up of 15.5 months. The mean life of prosthesis was 16 months with a range of 1-42 months. The ability to retain a successful trachea-esophageal speech in our series was $82 \%$. Eleven patients $(18 \%)$ were unable to maintain a prosthetic voice at the time of analysis (Table 2). Patients who continued to maintain their prosthetic voice after device replacements were not considered as failures of voice rehabilitation.

There was no significant difference in the prosthesis device life on correlation with age, co-morbidities, habitat, literacy status, pre-operative tracheostomy, setting of surgery, and the extent of surgery as depicted in Table 3.

\section{Discussion}

The history of voice rehabilitation following a total laryngectomy is in fact as long as the history of laryngectomy itself. Ever since the introduction of the TEP coupled with the use of voice prosthesis by Singer and Blom in 1980, the success of restoring vocal communication following laryngectomies has improved significantly.

The voice rehabilitation options include both surgical as well as nonsurgical methods; the nonsurgical methods include the electrolarynx, pneumatic artificial larynx, and esophageal speech while the surgical methods primarily includes TEP using voice prosthesis [1]. The multitude of methods which have been adopted over the years illustrates the difficulty of finding an optimal method of reestablishing verbal communication. The choice of voice rehabilitation is made keeping in mind the patient's communicative needs, physical and mental status, personal preferences and also based on the inputs from

Table 1 Stage distribution

\begin{tabular}{|c|c|c|}
\hline Stage distribution & Number & Adjuvant treatment \\
\hline $\begin{array}{l}\text { Bulky T3 tumors who were } \\
\text { aspiration/prior tracheosotomy }\end{array}$ & 17 & $\begin{array}{l}\text { PORT: } 13 \\
\text { Could not be given: } 4\end{array}$ \\
\hline T4a tumors & 37 & $\begin{array}{l}\text { PORT+CT- } 4 \\
\text { PORT- } 30 \\
\text { Could not be given- } 3\end{array}$ \\
\hline Salvage setting & 5 & No further therapy \\
\hline Sarcoma larynx & 1 & PORT \\
\hline
\end{tabular}


Table 2 Status of voice

prosthesis at the time of analysis

\begin{tabular}{lc}
\hline Status of voice prosthesis & Numbers \\
\hline Patients continuing to use the voice prosthesis WITHOUT any replacement & 37 \\
Patients continuing to use prosthesis WITH replacement & 12 \\
Patients in whom the prosthesis had to be REMOVED/extruded necessitating & 11 \\
TEP site closed (prosthetic voice failure) & \\
\hline
\end{tabular}

the surgeon and the speech language pathologist. Specific tissues pertaining to a voice prosthesis include details pertaining to the length of voice prosthesis, expense, diameter, type of retention collar, method of insertion, need for follow-up care, and the patient's ability to care for the prosthesis. For the past several decades, a voice prosthetic device has become the gold standard of voice rehabilitation for a majority of the laryngectomy patients, with the exception of the odd patient who has acquired good esophageal speech or for whom an external device is the only practical method of voice production [1-10].

The core principle of prosthetic voice rehabilitation is to use the lung-powered air for speech and to prevent the aspiration of ingested food material. To achieve this, the head and neck surgeon creates a fistula through the party wall that divides the trachea from the esophagus for insertion of a voice prosthesis either at the time of the total laryngectomy (primary TEP) or at a later time (secondary TEP). The voice prosthetic device has a one-way valve, which prevents aspiration and to allow passage of air from lung into the esophagus, which causes mucosal vibrations in the pharyngoesophageal segment and produces sound. This sound subsequently is further processed to intelligible speech in the oropharyngeal tract. The initial voice prosthesis was designed as ex-dwelling devices to be exclusively cared for by the patients, indwelling devices and the hands-free devices that need less dexterity on the part of the patient and can be cleaned in situ were subsequently developed followed by low-pressure devices.

In tracheoesophageal speech, the entire tidal volume of expired air $(500 \mathrm{ml})$ is available which is significantly more than the $40-70 \mathrm{ml}$ of air that is available for an esophageal speech, thus making the lung powered the speech louder, sustained, more fluent in quality, better intelligibility, and more closer to normal laryngeal speech. This is also objectively reflected as the better voice parameters, i.e., fundamental frequency, shimmer, jitter, words per minute, and better

Table 3 Life span of Prosthesis correlating with variables

\begin{tabular}{|c|c|c|c|c|c|c|}
\hline & & \multirow[t]{2}{*}{ No of patients } & \multicolumn{3}{|c|}{ Life of prosthesis } & \multirow[t]{2}{*}{$p$ value } \\
\hline & & & $<6$ months & 6-12 months & $>12$ months & \\
\hline \multirow[t]{3}{*}{ Age } & $<40$ years & 2 & 0 & 2 & 0 & \multirow[t]{3}{*}{0.32} \\
\hline & $40-60$ years & 36 & 3 & 9 & 24 & \\
\hline & $>60$ years & 22 & 4 & 8 & 10 & \\
\hline \multirow[t]{2}{*}{ Habitat } & Rural & 33 & 5 & 11 & 17 & \multirow[t]{2}{*}{0.93} \\
\hline & Urban & 27 & 2 & 8 & 17 & \\
\hline \multirow[t]{5}{*}{ Literacy } & Illiterate & 10 & 1 & 6 & 3 & \multirow[t]{5}{*}{0.29} \\
\hline & Primary & 9 & 2 & 4 & 3 & \\
\hline & Middle & 12 & 2 & 2 & 8 & \\
\hline & Secondary & 23 & 2 & 7 & 14 & \\
\hline & Graduate & 6 & 0 & 0 & 6 & \\
\hline \multirow[t]{3}{*}{ Co-morbids } & None & 35 & 6 & 12 & 17 & \multirow[t]{3}{*}{0.69} \\
\hline & One comorbid & 20 & 1 & 5 & 14 & \\
\hline & $>1$ comorbid & 5 & 0 & 2 & 3 & \\
\hline \multirow[t]{2}{*}{ Pre-op tracheostomy } & Not done & 38 & 13.9 & 25 & 61.1 & \multirow[t]{2}{*}{0.86} \\
\hline & Done & 22 & 0 & 45.5 & 54.5 & \\
\hline \multirow[t]{2}{*}{ Setting } & Primary & 55 & 7.4 & 33.3 & 59.3 & \multirow[t]{2}{*}{0.47} \\
\hline & Salvage & 5 & 25 & 25 & 50 & \\
\hline \multirow[t]{2}{*}{ Extent of primary surgery } & Laryngectomy alone & 43 & 7.1 & 33.3 & 59.6 & \multirow[t]{2}{*}{0.81} \\
\hline & With partial pharyngectomy & 17 & 12.5 & 33.3 & 56.3 & \\
\hline \multirow[t]{3}{*}{ Therapeutic neck dissection } & Done & 26 & 9.1 & 30.3 & 60.6 & \multirow[t]{3}{*}{0.89} \\
\hline & Not done & 34 & 8 & 36 & 56 & \\
\hline & Not received & 7 & & & & \\
\hline
\end{tabular}


maximum phonation time for the lung-powered speech. Voice rehabilitation after laryngectomy has in fact been revolutionized by use of TEP with voice prosthesis; many studies over the years have in fact reported its superiority to esophageal speech/electrolarynx speech [1-10].

A few studies have suggested that immediate rehabilitation with primary TEP and earlier voice restoration provide a positive psychological impact, a tendency towards better voice outcome and improved short-term quality of life [9] although many studies have shown both primary and secondary TEP to have identical success rates in voice rehabilitation [3]. The success rate of achieving a tracheoesophageal voice following total laryngectomy varies across the published studies between 70 and up to $95 \%$ in motivated long-term users, with a vast majority (88\%) achieving a fair-to-excellent voice quality.

A major limitation of voice prosthesis is its finite life span necessitating replacements [10-12]. The reasons for device/ voice failure can be attributed either due to TE puncture or prosthesis-related complications/problems or due to poor understanding or motivation of the patient. The device failure and the need for replacements impede communication and can potentially create enormous psychosocial and financial burdens to the patient. It is prudent to mention that apart from a proper patient selection, a meticulous technique of insertion, proper maintenance of the puncture site, and selection of adequately fitting prosthesis are additional key determinants of the device life. Different prostheses have different life spans, and the normal wear and tear of the valve will eventually cause leakage through the valve. New generation voice prostheses have a good life span of several months and need replacement in outpatient setting [13] and less than 3\% require general anesthesia for change of prosthesis.

It was initially believed that xerostomia following radiation may decrease prosthesis life span as it decreases the antibacterial and antifungal salivary peptides. A few studies including our study have found no difference in prosthesis life span with or without adjuvant radiation [14]; however, another study showed that radiotherapy doses to the primary tumor exceeding 60 Gray significantly shortened the mean voice prosthetic lifetime per patient [15]. In addition, yet another series further suggested that the addition of neck dissection along with postoperative radiotherapy does not affect short-term speech outcomes [16]. The addition of therapeutic neck dissection and adjuvant therapy did not affect the device life in our series as well. The mean prosthesis device life for laryngectomy patients who did not receive adjuvant radiation was not statistically different from those who received adjuvant treatment (19.28 months versus 16.87 months, $p=0.30$ ).

The common reasons of prosthesis replacement usually are fungal colonization, incompetent valve leading to endoprosthetic leak, widening of TEP leading to periprosthetic leak, prosthesis displacement, aspiration, granuloma formation, and stenosis of tracheostoma $[17,18]$.
Candida biofilm formation on the prosthetic surface can lead to deterioration of prosthesis, loosening and leakage requiring replacement. Antifungal agents have been advocated to tackle this problem and help prolong the life span of the prostheses $[19,20]$. However, the long-term use of antimicrobial and antifungal agents can potentially induce the development of resistant strains and hence needs to use with caution. It has further been suggested that the use of biosurfactants, probiotics, and targeted decontamination regimens may also help in preventing the microbial biofilm formation [20]. The use of anti-reflux therapy has been attempted to increase the life of the voice prosthesis [21-23].

Most of the studies on the association of dairy products and probiotics in increasing prosthesis lifespan had a finding of reduction in the growth of Candida albicans which produce enzymes, which can degrade the silicon biomaterial [24]. The traditional Indian-based diets of curd and buttermilk have been shown to prevent the candida colonization and improve prosthesis lifespan [25]. The longevity of the prosthesis in our cohort of patients could be partly attributed to this. This benefit is postulated due to the presence of Streptococcus thermophilus and Lactobacillus in the yoghurt [26]. Fluoroplastic material in the prosthesis valve which seems insusceptible to destruction by Candida species has been tied in an attempt to improve durability of voice prostheses [27].

Approximately one fourth of all patients with voice prostheses develop periprosthetic leaks within the first few years of deployment. TEP leaks were in fact the most common cause of prosthesis replacement in our study as well. An enlarged TEP site can cause a periprosthetic leak; this may be related to the use of a wide-diameter valve in a thin party wall [28]. Depending on the severity of fistula, the management options ranges from conservative to invasive approaches. Collagen, autologous fat injection, injection of hyaluronic acid, use of a silastic wafer or a purse string suture can potentially help improve the seal around the prosthesis and prevent leakage $[29,30]$. Insertion of small bore nasogastric tube can be used to allow shrinkage of fistula in the interim period which is followed by a subsequent prosthesis reinsertion.

A periprosthetic leak can also be caused by a too long prosthesis which moves like a piston in the TEP site, which can be corrected by downsizing the valve. An endoprosthetic leak usually demands a prosthesis replacement. Occasionally granulation tissue can form around the prosthesis at the TEP site as a result of trauma or chronic irritation to the mucosa, which can be easily cauterized or excised as was done in two of our patients. It is paramount to rule out the possibility of a tumor recurrence during the management of prosthetic leaks.

Occasionally extrusion of the voice prosthesis can occur during cleaning or following a bout of severe coughing. Failure to immediately replace the voice prosthesis may result in a stenosis of the puncture site necessitating a dilatation and reinsertion. In cases of severe stenosis, a surgical correction 
may be required if a spontaneous closure does not occur. Bronchial aspiration is a potentially life-threatening complication, which has been reported to occur in about $0.75-13 \%$ of patients. We had one patient who presented with aspiration of voice prosthesis into tracheobronchial tree which needed emergency bronchoscopic removal [31].

An important cause of voice failure is hypertonicity of the PE segment. An inadequately performed cricopharyngeal myotomy is an important cause of increased tonicity of the PE segment. The use of botulinum toxin to relieve constrictor hypertonicity has become the preferred method of management. A cricopharyngeal myotomy is generally reserved for circumstances in which the botulinum toxin injection has been ineffective in relieving the hypertonicity. Conversely, hypotonicity of the PE segment as a result of the loss or absence of muscular tone or when the PE lumen is large results in a weak and breathy voice. The outcome of surgical attempts to correct this problem has been varied; the use of prosthesis with a higher-resistance duckbill valve may be attempted. We did not observe any case of altered PE segment tonicity in our cohort of patients.

The prosthesis device life can also vary across regions due to number of reasons, including diet, patient preference, reimbursement and voice expectations, and tolerance of periods of minor leakage prior to replacement. The life of the voice prosthesis has been reported to be anywhere between 2 and 14 months based on the different group of patients, devices, and regions studied [10, 32-46] (Table 4).

In a very recent retrospective observational study of 390 laryngectomized patients, the authors reported a prosthesis device life much lower durability (mean 61 days) than historically reported which they attribute to the intensification of treatment regimens in an era of organ preservation which eventually complicates the TEP management [12].

The much longer prosthesis device life has been reported in studies from Africa, Portugal, and also from the Indian subcontinent. Cornu et al. who reported device life of 303 days in a South African patient population describe this phenomenon as patients taking "a more conservative approach" and this may have contributed to longer mean device life [32]. In a review by Sara Cruz et al. in Portugal, mean device life were 1-74 months for primary prosthesis and 1-24 months for secondary prosthesis [33]. Two Indian studies reported mean prosthesis longevity of 18 and 15 months, respectively [25, 44]. The mean life of our prosthesis was 16 months (142 months), which is similar to the experience of the other published Indian series (Table 4).

Interestingly, none of the factors analyzed in our cohort were significant determinants of the life of the prosthesis. We can therefore conclude that a primary TEP should be considered safe and feasible in properly selected and motivated patients of advanced laryngeal and hypopharyngeal carcinomas across all the clinical settings. Another interesting observation in our series is the fact that a majority of our patients
Table 4 Prosthesis lifespan as determined by various authors

\begin{tabular}{lll}
\hline $\begin{array}{l}\text { Authors } \\
\text { (number of patients) }\end{array}$ & Prosthesis type & $\begin{array}{l}\text { Mean device life } \\
\text { in months (range) }\end{array}$ \\
\hline Cornu [32] $(n=128)$ & Provox I & 10 \\
Hilgers [34] $(n=79)$ & Provox I & $7.8(0.2-24)$ \\
de Carpentier JP [35] $(\mathrm{n}=39)$ & Provox & $4.5(1.0-12)$ \\
Laccourreye O [36] $(n=37)$ & Provox & 10.3 \\
Heaton [37] $(n=40)$ & Provox II & $4.1(1.0-21)$ \\
Ackerstaff [38] $(n=292)$ & Provox I & $4.2(0.3-19.4)$ \\
Graville [39] $(n=30)$ & Provox II & $4.9(0.5-11)$ \\
Op de Coul [40] $(n=318)$ & Provox I & 5.4 \\
Schafer [41] $(n=58)$ & Provox I & 224 \\
& Provox II & 94 \\
Free [42] & Bloom Singer & 107 \\
Lequeux T [43] $(n=38)$ & Provox II & $2.8(0.3-12.4)$ \\
& Provox I & 10 \\
Ramalingam [44] $(n=41)$ & Provox II & 5 \\
Chaturvedi [25] $(n=60)$ & Provox I & 15 \\
Yenigun [45] $(n=28)$ & Provox II & $18(1.0-87)$ \\
Serra A [46] $(n=43)$ & Provox & $17.1(1.0-36)$ \\
& Provox I & 5 \\
Thylur DS [10] $(n=21)$ & Provox II & 4.1 \\
Lewin [12] $(n=390)$ & Provox Vega & 4.6 \\
Our series $(n=60)$ & Provox & 3.5 \\
\hline & Provox Vega & 2.17 \\
\hline & Provox 1/II & $2(1.2-2.3)$ \\
& & $16(1-42)$ \\
\hline & &
\end{tabular}

were reluctant for replacement of prosthesis for wear and tear and even in the presence of minor leaks. This tolerant approach may have contributed to the longer median device life in our cohort. However, the reasons for the wide variations of the device lives across the various published studies worldwide need to be investigated.

\section{Conclusion}

Our series has successfully demonstrated the safety and feasibility of using primary TEP coupled with the use of voice prosthesis for voice rehabilitation in properly selected and motivated patients of advanced laryngeal and hypopharyngeal carcinomas across all the clinical settings. Voice rehabilitation is a continuous ongoing process, not just about prosthesis and hence, careful attention must be directed towards the integrity of the pharyngoesophageal segment, voice prosthesis selection and insertion, and equally importantly troubleshooting. Meticulous adherence to the above principles can potentially increase the device life and make the prosthetic voice rehabilitation a safe, effective, and a financially viable option. Further objective assessments of voice outcomes, including prosthesis 
longevity are necessary to counsel patients and engage them in shared decision-making process regarding the voice rehabilitation options following laryngectomy and these issues incidentally are potential avenues for further research.

\section{References}

1. Tang CG, Sinclair CF (2015) Voice restoration after total laryngectomy. Otolaryngol Clin N Am 48:687-702

2. Abemayor E (2017) Prosthetic voice rehabilitation following laryngectomy: it's the archer not the arrow. JAMA Otolaryngol Head Neck Surg 143:72

3. Brown DH, Hilgers FJ, Irish JC, Balm AJ (2003) Postlaryngectomy voice rehabilitation: state of the art at the millennium. World J Surg 27:824-831

4. Chone CT, Gripp FM, Spina AL, Crespo AN (2005) Primary versus secondary tracheoesophageal puncture for speech rehabilitation in total laryngectomy: long-term results with indwelling voice prosthesis. Otolaryngol Head Neck Surg 133:89-93

5. van der Molen L, Kornman AF, Latenstein MN, van den Brekel MW, Hilgers FJ (2013) Practice of laryngectomy rehabilitation interventions: a perspective from Europe/the Netherlands. Curr Opin Otolaryngol Head Neck Surg 21:230-238

6. Guttman D, Mizrachi A, Hadar T, Bachar G, Hamzani Y, Marx S, Shvero J (2013) Post-laryngectomy voice rehabilitation: comparison of primary and secondary tracheoesophageal puncture. Isr Med Assoc J 15:497-499

7. Naunheim MR, Remenschneider AK, Scangas GA, Bunting GW, Deschler DG (2016) The effect of initial tracheoesophageal voice prosthesis size on postoperative complications and voice outcomes. Ann Otol Rhinol Laryngol 125:478-484

8. Cheng E, Ho M, Ganz C, Shaha A, Boyle JO, Singh B et al (2006) Outcomes of primary and secondary tracheoesophageal puncture: a 16-year retrospective analysis. Ear Nose Throat J 85:264-267

9. Polat B, Orhan KS, Kesimli MC, Gorgulu Y, Ulusan M, Deger K (2015) The effects of indwelling voice prosthesis on the quality of life, depressive symptoms, and self-esteem in patients with total laryngectomy. Eur Arch Otorhinolaryngol 272:3431-3437

10. Thylur DS, Villegas BC, Fisher LM, Sinha UK, Kokot N (2016) Device life of two generations of Provox voice prostheses. Ann Otol Rhinol Laryngol 125:501-507

11. Kress P, Schäfer P, Schwerdtfeger FP, Rösler S (2014) Are modern voice prostheses better? A lifetime comparison of 749 voice prostheses. Eur Arch Otorhinolaryngol 271:133-140

12. Lewin JS, Baumgart LM, Barrow MP, Hutcheson KA (2017) Device life of the tracheoesophageal voice prosthesis revisited. JAMA Otolaryngol Head Neck Surg 143:65-71

13. Glazer TA, Meraj T, Lyden TH, Spector ME (2016) In-office secondary tracheoesophageal puncture with immediate prosthesis placement. Otolaryngol Head Neck Surg 155:360-363

14. Gitomer SA, Hutcheson KA, Christianson BL, Samuelson MB, Barringer DA, Roberts DB, Hessel AC, Weber RS, Lewin JS, Zafereo ME (2016) Influence of timing, radiation, and reconstruction on complications and speech outcomes with tracheoesophageal puncture. Head Neck 38:1765-1771

15. Elving GJ, Van Weissenbruch R, Busscher HJ, Van Der Mei HC, Albers FW (2002) The influence of radiotherapy on the lifetime of silicone rubber voice prostheses in laryngectomized patients. Laryngoscope 112:1680-1683

16. Gultekin E, Yelken K, Garca MF, Develioglu ON, Kulekci M (2011) Effects of neck dissection and radiotherapy on short-term speech success in voice prosthesis restoration patients. J Voice 25: 245-248

17. Dayangku Norsuhazenah PS, Baki MM, Mohamad Yunus MR, Sabir Husin Athar PP, Abdullah S (2010) Complications following tracheoesophageal puncture: a tertiary hospital experience. Ann Acad Med Singap 39:565-564

18. Stafford FW (2003) Current indications and complications of tracheoesophageal puncture for voice restoration after laryngectomy. Curr Opin Otolaryngol Head Neck Surg. 11:89-95

19. Messing BP, Kim M, Hirata R, Thompson CB, Gebhart S, Sugar EA, Saunders JM, Sciubba J, Califano JA (2015) Evaluation of prophylaxis treatment of Candida in alaryngeal patients with tracheoesophageal voice prostheses. Laryngoscope 125:1118-1123

20. Somogyi-Ganss E, Chambers MS, Lewin JS, Tarrand JJ, Hutcheson KA (2017) Biofilm on the tracheoesophageal voice prosthesis: considerations for oral decontamination. Eur Arch Otorhinolaryngol 274:405-413

21. Lorenz KJ, Grieser L, Ehrhart T et al (2010) Prosthetic voice restoration after laryngectomy. The management of fistula complications with anti-reflux medications. HNO 58:919-926

22. Lorenz KJ, Kraft K, Graf F et al (2015) Importance of cellular tight junction complexes in the development of periprosthetic leakage after prosthetic voice rehabilitation. HNO 63:171-181

23. Pattani KM, Morgan M, Nathan CO (2009) Reflux as a cause of tracheoesophageal puncture failure. Laryngoscope 119:121-125

24. Soukka T, Tenovuo J, Lenander-Lumikari M (1992) Fungicidal effect of human lactoferrin against Candida albicans. FEMS Microbiol Lett 69:223

25. Chaturvedi P, Syed S, Pawar PV, Kelkar R, Biswas S, Datta S, Nair D, Chaukar D, D'cruz AK (2014) Microbial colonization of Provox voice prosthesis in the Indian scenario. Indian J Cancer 51:184-188

26. Busscher HJ, van Hoogmoed CG, Geertsema-Doornbusch GI, van der Kuijl Booij M, van der Mei HC (1997) Streptococcus thermophilus and its biosurfactants inhibit adhesion by Candida spp. on silicone rubber. Appl Environ Microbiol 63:3810-3817

27. Timmermans AJ, Harmsen HJ, Bus-Spoor C, Buijssen KJ, van AsBrooks C, de Goffau MC, Tonk RH, van den Brekel MW, Hilgers FJ, van der Laan BF (2016) Biofilm formation on the Provox ActiValve: composition and ingrowth analyzed by Illumina paired-end RNA sequencing, fluorescence in situ hybridization, and confocal laser scanning microscopy. Head Neck 38 Suppl 1: E432-E440

28. Jiang N, Kearney A, Damrose EJ (2016) Tracheoesophageal fistula length decreases over time. Eur Arch Otorhinolaryngol 273:1819 1824

29. Friedlander E, Pinacho Martínez P, Poletti Serafini D, MartínOviedo C, Martínez Guirado T, Scola Yurrita B (2016) Practical management of periprosthetic leakage in patients rehabilitated with a Provox ${ }^{\circledR} 2$ voice prosthesis after total laryngectomy. Acta Otorrinolaringol Esp 67:301-305

30. Erdim I, Sirin AA, Baykal B, Oghan F, Guvey A, Kayhan FT (2016) Treatment of large persistent tracheoesophageal peristomal fistulas using silicon rings. Braz J Otorhinolaryngol. https://doi.org/ 10.1016/j.bjorl.2016.06.011

31. Krishnamurthy A (2014) A novel approach in the management of an aspirated voice prosthesis in a laryngectomized patient. Indian J Surg Oncol 5:255-256

32. Cornu AS, Vlantis AC, Elliott H, Gregor RT (2003) Voice rehabilitation after laryngectomy with the Provox voice prosthesis in South Africa. J Laryngol Otol 117:56-59

33. Cruz S, Viana R, Guimarães J, Fernandes J (2014) Joaquim Castro Silva, Eurico Monteiro, Tracheoesophageal voice prosthesis outcomes: success or Insucess? Int J Otolaryngol Head Neck Surg 3: 14-22 
34. Hilgers FJ, Schouwenburg PF (1990) A new low-resistance, selfretaining prosthesis (Provox) for voice rehabilitation after total laryngectomy. Laryngoscope 100:1202-1207

35. de Carpentier JP, Ryder WD, Saeed SR, Woolford TJ (1996) Survival times of Provox valves. J Laryngol Otol 110:37-42

36. Laccourreye O, Ménard M, Crevier-Buchman L, Couloigner V, Brasnu D (1997) In situ lifetime, causes for replacement, and complications of the Provox voice prosthesis. Laryngoscope 107: 527-530

37. Heaton JM, Parker AJ (1994) Indwelling tracheo-oesophageal voice prostheses post-laryngectomy in Sheffield, UK: a 6-year review. Acta Otolaryngol 114:675-678

38. Ackerstaff AH, Hilgers FJ, Meeuwis CA et al (1999) Multiinstitutional assessment of the Provox 2 voice prosthesis. Arch Otolaryngol Head Neck Surg 125:167-173

39. Graville D, Gross N, Andersen P, Everts E, Cohen J (1999) The longterm indwelling tracheoesophageal prosthesis for alaryngeal voice rehabilitation. Arch Otolaryngol Head Neck Surg 125:288-292

40. Op de Coul BM, Hilgers FJ, Balm AJ, Tan IB, van den Hoogen FJ, van Tinteren H (2000) A decade of postlaryngectomy vocal rehabilitation in 318 patients: a single institution's experience with consistent application of provox indwelling voice prostheses. Arch Otolaryngol Head Neck Surg 126:1320-1328
41. Schafer P, Klutzke N, Schwedtfeger FP (2001) Voice restoration with voice prosthesis after total laryngectomy. Assessment of survival time of 378 Provox-1, Provox-2 and Blom-Singer voice prosthesis. Laryngorthinootologie 80:667-681

42. Free RH, Busscher HJ, Elving GJ, van der Mei HC, van Weissenbruch R, Albers FW (2001) Biofilm formation on voice prostheses: in vitro influence of probiotics. Ann Otol Rhinol Laryngol 110:946-951

43. Lequeux T, Badreldin A, Saussez S, Thill MP, Oujjan L, Chantrain G (2003) A comparison of survival lifetime of the Provox and the Provox2 voice prosthesis. J Laryngol Otol 117:875-878

44. Ramalingam W, Chikara D, Rajagopal G, Mehta AR, Sarkar S (2007) Tracheo-esophageal puncture (TEP) for voice rehabilitation in laryngectomised patients Blom-singer ${ }^{\circledR}$ vs Provox ${ }^{\circledR}$ prosthesis : our experience. Med J Armed Forces India 63:15-18

45. Yenigun A, Eren SB, Ozkul MH, Tugrul S, Meric A (2015) Factors influencing the longevity and replacement frequency of Provox voice prostheses. Singap Med J 56:632-636

46. Serra A, Di Mauro P, Spataro D, Maiolino L, Cocuzza S (2015) Post-laryngectomy voice rehabilitation with voice prosthesis: 15 years' experience of the ENT Clinic of University of Catania. Retrospective data analysis and literature review. Acta Otorhinolaryngol Ital 35:412-419 